\title{
Exploring the hardship of ease: Subjective and objective effort in the ease-of-processing paradigm
}

\author{
Bettina von Helversen • Guido H. E. Gendolla • \\ Piotr Winkielman $\cdot$ Ralph E. Schmidt
}

Published online: 20 March 2008

(C) The Author(s) 2008

\begin{abstract}
Numerous studies examined the role of processing effort in judgments using the "ease-of-processing" paradigm in which participants generate or retrieve few or many issue-relevant thoughts. Because earlier studies only assessed the subjective effort, it is unclear if this paradigm also mobilizes objective effort, and how such effort relates to subjective effort. These questions were addressed in two experiments modeled on standard tasks from the processing effort literature: "ease of argument generation" (Study 1) and "ease of retrieval" (Study 2). In both experiments we simultaneously measured subjective effort (via self-report) and objective effort (via cardiovascular reactivity). The results showed that processing ease manipulations (generation or retrieval of few vs. many exemplars) influence not only subjective effort, but also objective effort, as reflected especially by increases of systolic blood pressure in the many exemplars condition. However, only subjective effort was related to judgment. In the discussion, we consider the role of various forms of effort and other relevant variables in "processing ease" effects.
\end{abstract}

B. von Helversen $(\square)$

Max Planck Institute for Human Development,

Adaptive Behavior and Cognition, Lentzeallee 94, 14195 Berlin, Germany

e-mail: vhelvers@mpib-berlin.mpg.de

G. H. E. Gendolla - R. E. Schmidt

Department of Psychology, University of Geneva, Geneva, Switzerland

P. Winkielman

Department of Psychology, University of California,

San Diego, La Jolla, CA, USA
Keywords Effort - Ease of processing . Cognitive feelings

\section{Introduction}

There is increasing evidence that cognitive experiences influence judgment and behavior (Schwarz 1998). Examples of cognitive experiences include feelings of familiarity (Jacoby et al. 1989; Fazendeiro et al. 2005), boredom (Csikszentmihalyi 1975), or surprise (Gendolla and Koller 2001). Much research in this area examines how attitudes and judgments are influenced by experiences related to mental processing effort (see Schwarz and Clore 2006, for a review). In the present research we focus on the "accessibility experience" (see Schwarz 1998), which refers to a broad sense of effort in a cognitive task and is typically investigated with paradigms that involve retrieval or generation of a large amount of information.

Most research on "accessibility experiences" has relied on self-reports of subjectively experienced effort—usually assessed as ratings of task difficulty-and ignored the objective effort invested. This has left several questions unaddressed. First, is effort only subjectively experienced or also objectively mobilized in the ease-of-processing paradigm? Second, if objective effort is mobilized, how does it relate to subjective effort? Finally, how does subjective and objective effort relate to the standard judgmental effects of processing ease manipulations? In the present research we address these questions by simultaneously investigating the role of subjective and objective effort in the "ease-of-retrieval" and the "ease-of-argument-generation" paradigms. Our current studies build on earlier findings that objective effort can be accurately 
assessed with psychophysiological means (see Gendolla and Brinkmann 2005; Wright and Kirby 2001 for reviews).

Ease effects on judgments

The idea that processing effort influences judgments goes back to the notion of the availability heuristic, which proposes that people estimate event frequency and probability "by the ease with which instances or associations come to mind" (Tversky and Kahneman 1973, p. 208). However, initial experimental tests of the availability heuristic did not distinguish whether judgments are primarily based on the amount of accessible information (i.e., retrieval content) or the experience of accessibility (i.e., retrieval effort). To address these issues, Schwarz and colleagues (1991) designed a very influential "few-many" paradigm (traditionally referred to as "ease-of-processing" paradigm) which pits the amount of accessible information against the subjective effort of retrieving that information. In this paradigm, some participants retrieve or generate many thoughts, which results in more accessible information, but also higher subjective difficulty. Other participants retrieve or generate few thoughts, which results in less accessible information, but also lower difficulty. Interestingly, the results suggest that retrieval effort can override the amount of retrieved information. For example, in one study participants who recalled 12 assertive behaviors later rated themselves as less assertive than did participants who had recalled only 6 assertive behaviors. This paradoxical effect presumably occurs because the difficulty of recalling 12 assertive behaviors indicates to participants that they cannot be very assertive. Since then numerous studies with the ease-of-processing paradigm have shown parallel effects in domains as diverse as quality of one's own childhood memory (Winkielman et al. 1998), behavioral frequencies (Aarts and Dijksterhuis 1999), happiness (Winkielman and Schwarz 2001), health risks (Rothman and Schwarz 1998), commercial products (Wänke et al. 1997), and attitude formation (Wänke et al. 1996).

Subjective and objective effort

As stated earlier, the role of objectively mobilized effort in the ease-of-processing paradigm is unclear as this issue has never been investigated. Assessing subjectively experienced and objectively mobilized effort simultaneously allows testing three possible hypotheses concerning the role of objective effort: (1) There is no objective effort involved in the ease-ofprocessing paradigm; (2) objective effort is mobilized, but judgment effects are primarily driven by subjective effort; and (3) objective effort is mobilized and plays a critical role in the judgment effects.

To test these possibilities, actually mobilized effort must be assessed by other means than by self-reports. In general, individuals have trouble accurately reporting on their internal states (Nisbett and Wilson 1977; Silvia and Gendolla 2001), including effort (Morsella 2005). Self-reports can also be systematically biased due to communicative issues (Schwarz 1999) and self-presentational concerns (Pyszczynski and Greenberg 1987). More specifically, in the multi-item ease paradigm, the ratings of effort could reflect several variables other than actual effort. For example, after generating or retrieving many as opposed to few items (e.g., 12 vs. 4), participants could rate the task as hard because they performed more cognitive steps, came closer to running out of relevant recall content, or took more time than expected. In short, when asked about "effort", participants in the many event condition may self-report greater difficulty without actually having to mobilize more resources than do participants in the few events condition.

\section{Measuring effort mobilization objectively}

There is ample evidence that cardiovascular reactivityi.e., the changes in the activity of the heart and the vasculature in the context of task performance-is a very adequate operationalization of objective task engagement or effort mobilization. According to Wright's (1996) integration of motivational intensity theory (Brehm et al. 1983; Brehm and Self 1989) with Obrist's (1981) "active coping" approach to cardiovascular arousal, the impact of the sympathetic nervous system on the heart and the vasculature is proportional to the actual level of subjective task difficulty, as long as success is possible and worthwhile. These cardiovascular effects are independent of metabolic demand and can be observed in cognitive tasks involving mental effort (e.g., in attention or memory tasks; see Gendolla and Brinkmann 2005; Wright and Kirby 2001 for reviews).

Among common indices of cardiovascular activity, systolic blood pressure (SBP) responds most sensitively to task demand (e.g., Gendolla and Krüsken 2002; Gerin et al. 1995; Light 1981; Obrist et al. 1974; Obrist 1981; Sherwood et al. 1990; Smith et al. 2000; Wright et al. 2003). This is because, besides vascular resistance, systolic pressure depends on the contractility of the heart muscle. Contractility is determined by $\beta$-adrenergic sympathetic discharge to the heart (Brownley et al. 2000), which systematically responds to the experienced difficulty to perform a task (Obrist 1981; Wright 1996). The task-related adjustments of diastolic blood pressure (DBP) and heart rate (HR) are less systematic. DBP depends on vascular resistance, which is unsystematically affected by sympathetic arousal. HR is determined by both sympathetic and parasympathetic arousal and thus only responds to effort mobilization to the extent to which the sympathetic impact is stronger (e.g., Berntson et al. 1993; Obrist 1981). 


\section{The present research}

Two experiments investigated the role of subjective and objective effort in standard ease-of-processing paradigms-ease-of-argument-generation (Experiment 1) and ease-of-retrieval (Experiment 2). Our goals were (1) to measure the objectively mobilized and subjectively experienced effort, and (2) to examine how these variables contribute to ease-of-processing effects on resulting attitudes and judgments.

\section{Experiment 1: Ease-of-argument generation}

This experiment investigated the influence of effort involved in argument generation on attitudes using a procedure based on Wänke et al. (1996). Participants first generated few (easy condition) or many (difficult condition) arguments in favor of public transportation. Subsequently, we measured attitudes towards the public transport system. Based on previous research, we predicted more negative attitudes towards public transportation in the difficult condition. In addition to the subjective effort of argument generation, this experiment included measures of objectively mobilized effort in terms of cardiovascular reactivity. We predicted that participants in the difficult condition would experience higher subjective effort (Schwarz 1998) and mobilize more objective effort in terms of cardiovascular reactivity (Wright and Kirby 2001).

\section{Method}

\section{Participants and design}

Twenty university students (average age 23.45 years, $S D=3.35$ ) with various majors (psychology excluded, because of prior knowledge about similar tasks) were randomly assigned to either one of two experimental conditions: easy or difficult argument generation in favor of public transport. Because of possible gender differences in cardiovascular activity (see Brownley et al. 2000) and the use of public transport among students, we decided to run this first test of our predictions only on men, who were better accessible at the time the study was conducted. All respondents received 5 Swiss Francs (4 USD) for participation.

\section{Apparatus and physiological measures}

The cardiovascular measures were assessed with a computer-aided monitor (Par Electronics Physioport III). SBP (millimeters of mercury $[\mathrm{mmHg}])$ and DBP $(\mathrm{mmHg})$ were determined by oscillometry. HR (beats per minute [bpm]) was determined by tabulation of oscillations in the cuff. A blood pressure cuff was placed over the brachial artery above the elbow of participants' nondominant arm. The cuff was automatically inflated and assessed values were stored on a computer disk. One cardiovascular measure took approximately $35 \mathrm{~s}$.

\section{Procedure}

The study was described as an investigation in physiological activity during task performance. Participants attended the session individually. After having provided informed consent, they took a seat in front of the computer screen, and the experimenter attached the blood pressure cuff. Experimental materials were prepared such that there was no need for extraneous movement. After the collection of biographical data (age, major, gender), the session proceeded with an $8 \mathrm{~min}$ habituation period to determine physiological baseline values. Cardiovascular measures were repeatedly taken in 1 min intervals (i.e., 7 measures).

After the habituation period, participants in the easy condition were asked to produce 4 different arguments in favor of using public transport in $6 \mathrm{~min}$. Participants in the difficult condition received the same instructions, but were asked to formulate 12 arguments. Once participants had read the instructions and indicated that they were ready to start, they completed the argument generation task. During the 6 min of task performance, 6 cardiovascular measures were taken in intervals of $1 \mathrm{~min}$, starting at the moment of task onset. After the argument generation task, participants answered a questionnaire adapted from Wänke et al. (1996). Specifically, participants answered the direct question "How attractive do you consider public transportation" on a scale ranging from not attractive (1) to very attractive (10), and the indirect question "Are you in favor of more restrictions against private vehicles?" on a scale ranging from no, not at all (1) to yes, very much (10). For both measures, higher ratings indicated a more positive attitude toward public transportation. Participants also rated their experience during the argument generation task by responding to two related questions. First, they indicated their difficulty in generating arguments ("How difficult was it to describe the requested number of arguments?") on a scale ranging from not difficult at all (1) to very difficult (10). Second, they indicated the amount of effort they had mobilized for argument generation ("How effortful was it to describe the requested number of arguments?") on a scale ranging from not effortful at all (1) to very effortful (10). Finally, participants were probed for suspicion, debriefed, and received their payment. 
Results

\section{Task performance and ratings of subjective effort}

Our task manipulation was successful. Participants in the difficult condition generated significantly more arguments $(M=8.80, S D=2.25)$ than in the easy condition $(M=3.80, S D=0.42), t(18)=6.09, p<.001$, Cohen's $d=3.09$. Given that participants' ratings of difficulty and invested effort were highly correlated, $r(20)=.75$, $p<.001$, we created a subjective effort index by averaging the two measures. As expected, generating arguments in favor of public transportation was rated as significantly more effortful in the difficult condition $(M=6.90, S D=1.42)$ than in the easy condition $(M=3.80, S D=1.49)$, $t(18)=4.74, p<.001, d=2.13$, (see Fig. 1, left panel).

\section{Cardiovascular measures}

To analyze cardiovascular reactivity we first computed cardiovascular baseline values by taking the averages of the last two measures of each assessed parameter, given that for all of them, the last two measures did not differ significantly from one another. Then, we computed cardiovascular change (delta) scores for each participant by subtracting the baseline values from the averages of values obtained during task performance (see blood pressure publication guidelines by Shapiro et al. 1996). As the SBP baselines differed between conditions (easy: $M=116.55, S D=5.32$; difficult: $M=103.30, S D=6.78), t(18)=4.86, p<.001$, $d=2.24$, we conducted preliminary ANCOVAs to test for associations between the cardiovascular baseline values and reactivity scores (e.g., Llabre et al. 1991) in order to determine if we needed to adjust the reactivity scores with regard to the baseline values. These analyses found only a trend towards a significant association between the HR baselines and reactivity scores, $F(1,17)=3.88, p=.07$, $\eta^{2}=.19$, and no significant associations between baselines and reactivity scores for $\operatorname{SBP}$ and $\operatorname{DBP}(F \mathrm{~s}[1,17]<1.89$, $\left.p s>.28, \eta^{2} \mathrm{~s}<.10\right)$. Consequently, we used non-adjusted reactivity scores in the further analysis.

As expected, systolic reactivity was significantly stronger in the difficult $(M=10.50, S D=5.44)$ than in the easy condition $(M=3.89, S D=5.76), \quad t(18)=2.46$, $p<.05, d=1.18$, (see Fig. 1, middle panel). The same effect emerged for $\mathrm{HR}$ reactivity (difficult: $M=9.90$, $S D=4.69$; easy: $M=-0.20, S D=6.76), t(18)=3.88$, $p<.001, d=1.71$. Note that the HR effect remained significant, $F(1,17)=8.67, p<.05, \eta^{2}=.34$, after controlling for the HR baselines as covariate (see above). The effect on diastolic reactivity pointed in the same direction as those obtained on SBP and HR reactivity (difficult: $M=7.28, S D=5.02$; easy: $M=4.71, S D=5.37$ ) but failed to be significant, $t(18)=1.11, p<.29, d=.49$.

\section{Attitude measure}

Participants' attitude about public transport in general was favorable $(M=7.25, S D=2.08)$ and more positive than their attitude towards restrictions on private vehicles $(M=5.75, S D=2.59), t(18)=2.06, p<.05, d=.72$. This highly positive attitude suggests that it was precomputed and that the effort manipulation thus should have more impact on participants' attitude towards restrictions on private cars, an issue our participants had more mixed feelings about and probably had not reflected upon. Indeed, in the difficult condition (i.e., after generating many propublic-transportation arguments), participants were less in favor of restrictions against private vehicles $(M=4.60$, $S D=2.91$ ) than in the easy condition (i.e., after generating few pro-public-transportation arguments) $(M=6.90$, $S D=1.66), t(18)=2.17, p<.05, d=.97$ (see Fig. 1, right panel). This replicated the standard "effort" effect, with participants' relying on the accessibility experience rather than the number of arguments in constructing their judgment. The manipulation effect on the direct attitude measure was, by contrast, not significant, $M_{\text {easy }}=6.80$, $S D=2.20$ vs. $M_{\text {difficult }}=7.70, S D=1.95, t(18)=0.97$, $p<.35, d=.43$.
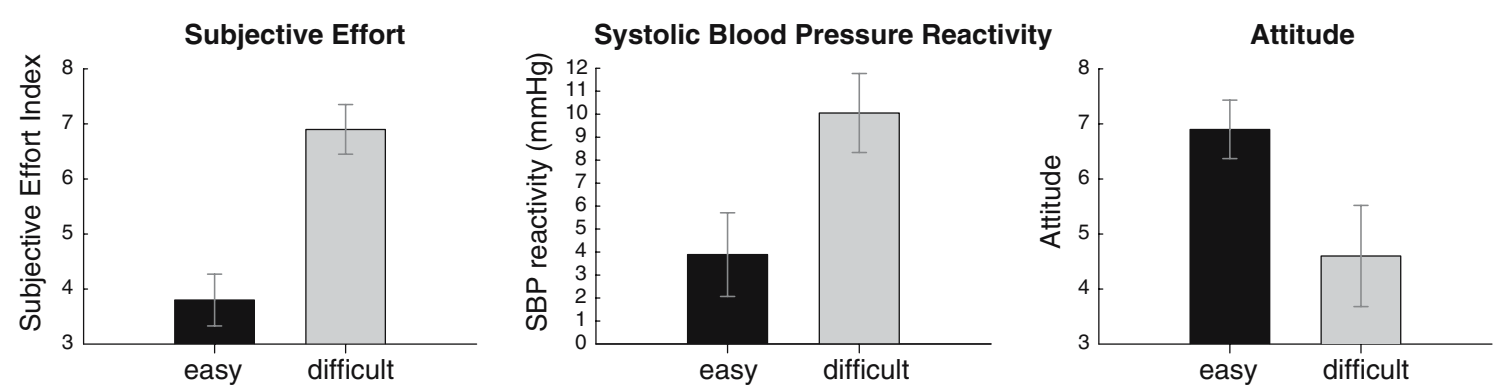

Fig. 1 Cell means and standard errors of subjective effort during the argument generation task (left panel), systolic blood pressure reactivity during argument generation (middle panel), and the attitude measure (right panel) in Experiment 1 
Table 1 Zero-order correlations between the difficulty manipulation, subjective effort, SBP reactivity, and attitude in Experiment 1

\begin{tabular}{llll}
\hline Variables & Subjective effort & SBP reactivity & Attitude \\
\hline Difficulty manipulation & $.75^{* * *}$ & $.50^{*}$ & $-.46^{*}$ \\
Subjective effort & & .29 & -.29 \\
SBP reactivity & & & -.02 \\
\hline
\end{tabular}

$N=20 . \mathrm{SBP}=$ systolic blood pressure reactivity. $* p \leq .05$ level, $* * * p \leq .001$ (two-tailed)

\section{Correlation analysis}

To understand how subjective effort and objective effort related to the judgment effects we analyzed the zero-order correlations between the variables of interest. As shown in Table 1, the difficulty manipulation, subjective effort, SBP reactivity as most sensitive measure of objective effort, and the indirect attitude measure were significantly correlated. Moreover, subjective effort was positively related to SBP, and, as expected, negatively to the attitude about restricting private vehicles. Although these correlations did not attain the conventional level of significance $(p s<.21)$, it is of note the correlation between systolic reactivity and attitude was close to zero.

\section{Discussion}

Generating many, as opposed to few, arguments for public transportation was not only subjectively experienced as more difficult, but also elicited more objective effort in terms of cardiovascular reactivity. These findings clearly indicate that the ease-of-processing paradigm involves changes in both subjective and objective effort. Further, the indirect measure of attitude showed the standard "ease" effect-with participants being more favorable towards private transportation when forced to recall more, rather than fewer, arguments in favor of public transportation. This finding suggests that objective effort could potentially play a role in the ease-of-processing effects on attitudes. However, our analysis also suggested that subjectively experienced rather than objectively mobilized effort was related to the attitude effect, although - most probably due to the small sample size-the correlation between subjective effort and the attitude measure did not attain the conventional level of significance.

\section{Experiment 2: Ease of retrieval}

This experiment sought to conceptually replicate Experiment 1 and to extend our investigation to another domain of "ease" effects. We used a similar procedure as Schwarz et al. (1991), who found that the ease of retrieval of assertive episodes influences judgments of assertiveness more than the number of retrieved instances. In addition, we included the same measures of objectively mobilized effort as in Experiment 1. Ease of retrieval was manipulated by instructing participants to either recall few or many instances of their past behavior. To manipulate the valence of the recalled behavior, participants retrieved situations in which they had acted either assertively or unassertively. We predicted again greater subjective effort and greater effort-related cardiovascular reactivity in the difficult conditions than in the easy conditions. Moreover, following Schwarz et al. (1991), we predicted that remembering many assertive behaviors (difficult) would result in lower assertiveness ratings than recalling few assertive behaviors (easy), with reverse effects being obtained when participants recall unassertive behaviors.

\section{Method}

\section{Participants and design}

Fifty-two university students with various majors were randomly assigned to the conditions of a 2 (difficulty: easy vs. difficult) $\times 2$ (assertiveness: assertive vs. unassertive) between-persons design, balanced for gender. Psychology majors in their second year or higher were excluded because of their prior experiences with similar manipulations. Later on, 4 participants had to be excluded from the analyses because their cardiovascular measures contained too many missing data due to technical measurement problems. This left 48 participants ( 40 women, 8 men) with an average age of 21.98 years $(S D=3.26)$. The study lasted for about $30 \mathrm{~min}$. Participants received course credits for their participation.

\section{Materials, measures, and procedure}

The cardiovascular measures were collected with the same apparatus as in Experiment 1 and the procedure was also similar. An exception was that we assessed the cardiovascular measures in 2 min intervals to prevent discomfort that could interfere with the expected cognitive experiences. Participants were told that the study investigated memory effects on physiological responses. After collection of demographic data and attachment of the blood pressure cuff, cardiovascular measures were assessed during a $10 \mathrm{~min}$ habituation period in $2 \mathrm{~min}$ intervals (i.e., 5 measures) to determine cardiovascular baselines. Subsequently, participants received instructions to recall either 4 (easy) or 11 (difficult) situations in which they had felt assertive (assertive condition) or unassertive (unassertive condition) within 6 min. During the retrieval task, participants' cardiovascular responses were recorded in $2 \mathrm{~min}$ 
intervals (i.e., 3 measures). Adapted from Schwarz et al. (1991), participants then judged their assertiveness ("How assertive are you?") on a scale ranging from not at all assertive (0) to very assertive (10) and their unassertiveness ("How unassertive are you if you interact with others?") on a scale ranging from not at all unassertive (0) to very unassertive (10). Next, participants indicated again the experienced difficulty of the retrieval task (not at all difficult [0] to very difficult [10]) and the effort they had mobilized (not effortful at all [0] to very effortful [10]), to assess subjective effort. Finally, participants were probed for suspicion and debriefed.

Results

Given that the number of men was relatively small, we tested with preliminary 2 (assertiveness) $\times 2$ (difficulty) ANCOVAs, with gender as covariate, if gender had any significant influence on the main dependent variablescardiovascular reactivity, subjective effort, and the assertiveness judgments. Because these analyses found no significant gender effects $(F \mathrm{~s}[1,44]<1.56, p \mathrm{~s}>.21$, $\left.\eta^{2}<.04\right)$ this factor was not further considered in the analyses reported below.

\section{Task performance and subjective effort}

The manipulation of task performance was successful. A 2 (difficulty) $\times 2$ (assertiveness) between-persons ANOVA on the number of retrieved examples revealed a large difficulty main effect due to a greater number of retrieved situations in the difficult condition $(M=8.04, S D=2.05$ vs. $M=4.00, S D=0.00), F(1,44)=88.93, p<.001$, $\eta^{2}=.67$, and no effect of assertiveness, $F$ s $[1,44]<1$, $p s>.92, \eta^{2}<.01$.

Given that the ratings of experienced task difficulty and invested effort were highly correlated, $r(48)=.63$, $p<.001$, we averaged them to a subjective effort index. A 2 (difficulty) $\times 2$ (assertiveness) between-persons ANOVA on this index revealed the expected difficulty main effect, $F(1,44)=21.08, p<.001, \eta^{2}=.32$, indicating higher effort in the difficult $(M=5.56, S D=2.37)$ than in the easy condition $(M=3.02, S D=1.80)$. Unexpectedly, the assertiveness main effect, $F(1,44)=4.77$, $p<.05, \eta^{2}=.10$, and the interaction were also significant, $F(1,44)=6.55, p<.05, \eta^{2}=.13$. Inspection of the cell means (see Fig. 2, left panel) revealed significantly lower demand in the easy-assertive $(M=2.92, S D=1.58)$ than in the difficult-assertive cell $(M=6.88, S D=2.11)$, $t(44)=5.06, p<.001, d=2.12$. However, in the unassertive condition, the easy $(M=3.13, S D=2.06)$ and the difficult $(M=4.25, S D=1.87)$ cells did not differ reliably, $t(44)=1.40, p>.15, d=.57$.

\section{Cardiovascular measures}

The last two cardiovascular measures taken during the habituation period constituted the cardiovascular baselines. According to 2 (difficulty) $\times 2$ (assertiveness) ANOVAs, there were no significant baseline differences between the conditions for any of the three assessed cardiovascular indices (all $F \mathrm{~s}[1,44]<1.65, p \mathrm{~s}>.30, \eta^{2} \mathrm{~s}<.04$ ). After creating reactivity scores, we first tested with ANCOVAs if the cardiovascular reactivity scores were significantly associated with the respective baselines. Because none of these associations were significant we conducted all further analyses without baseline corrections.

A 2 (difficulty) $\times 2$ (assertiveness) ANOVA of SBP reactivity revealed a significant interaction, $F(1$, 44) $=8.00, p<.008, \eta^{2}=.15$, in absence of significant main effects $\left(F \mathrm{~s}<1.01, p \mathrm{~s}>.31, \eta^{2}<.03\right)$. Comparison of cell means (see Fig. 2, middle panel) found for the assertive condition that systolic reactivity was, as expected, significantly stronger in the difficult condition $(M=10.50$, $S D=6.64)$ than in the easy condition $(M=3.61$, $S D=4.98), \quad t(44)=2.59, \quad p<.05, d=1.17$. In the unassertive condition, however, the easy $(M=7.02$, $S D=8.48)$ and difficult $(M=3.29, S D=5.35)$ cells did not differ significantly, $t(44)=1.40, p>.16, d=.52$. Together with the effects on subjective effort, this finding
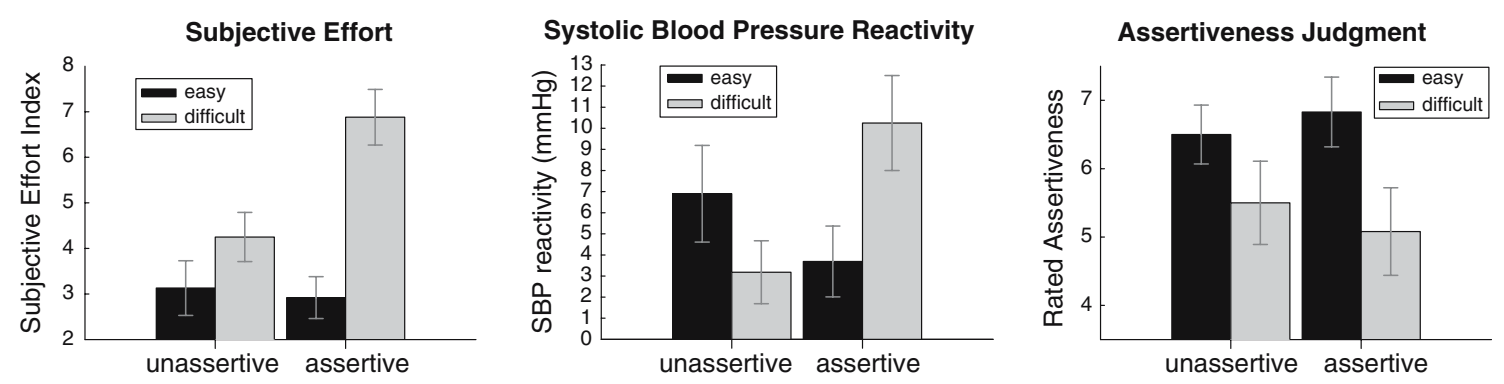

Fig. 2 Cell means and standard errors of subjective demand of the retrieval task (left panel), systolic blood pressure reactivity during retrieval (middle panel), and assertiveness judgments (right panel) in Experiment 2 
indicates that the difficulty manipulation was only effective in the assertive condition. The 2 (difficulty) $\times 2$ (assertiveness) ANOVA of DBP reactivity found no significant effects $\left(F \mathrm{~s}<1, \quad p \mathrm{~s}>.34, \quad \eta^{2} \mathrm{~s}<.02\right)$. An analogous ANOVA for HR reactivity only revealed a main effect of assertiveness, $F(1,44)=4.24, p<.05, \eta^{2}=.09$, indicating weaker reactivity in the unassertive condition $(M=2.71, S D=4.91)$ than in the assertive condition $(M=7.38, S D=9.75)$. No other effect approached significance $\left(F \mathrm{~s}<1, p \mathrm{~s}>.50, \eta^{2} \mathrm{~s}<.01\right)$.

\section{Assertiveness judgments}

We recoded the two items measuring assertiveness so that higher scores indicated higher assertiveness, and we assessed their correlation. As the two items correlated only moderately, $r(48)=.43, p<.01$, we analyzed them separately. In the following we will concentrate on the assertiveness item, as there were no significant effects for the item measuring unassertiveness in the contact with others $\left(F \mathrm{~s}[1,44]<1, p \mathrm{~s}>.66, \eta^{2} \mathrm{~s}<.01\right)$.

As discussed, our recall manipulation influenced subjective and objective effort in the assertive condition, but had no effects in the unassertive condition. Similarly, the effort manipulation only influenced the judgments in the assertive condition. Correspondingly, participants in the assertive condition judged their assertiveness as lower $(M=5.08, S D=2.23)$ after recalling many assertive situations (difficult), than they did after recalling fewer assertive situations (easy) $(M=6.83, \quad S D=1.80)$, $t(44)=2.11, p<.05, d=.86$ (see the right panel of Fig. 2). However, in the unassertive condition, the assertiveness ratings did not differ reliably between the easy $(M=6.50, S D=1.45)$ and the difficult $(M=5.50$, $S D=2.11)$ cells, $t(22)=1.35, p>.20, d=.55 . \quad$ In addition, there was a difficulty main effect, with participants rating themselves as generally less assertive after listing many examples $(M=6.67, S D=1.01$ vs. $M=$ $5.29, S D=2.14), F(1,44)=6.14, p<.02, \eta^{2}=.12$. No other effect approached significance $(F \mathrm{~s}(1,44)<1$, $\left.p s>.50, \eta^{2}<.01\right)$.

An analysis of the zero-order correlations between the difficulty manipulation, subjective effort, SBP reactivity, and the assertiveness judgments in the assertive condition-where the manipulations had significant effectsrevealed similar results as Study 1 (see Table 2). The assertiveness judgment was negatively related to subjective effort. Unlike Study 1, the assertiveness judgment was also negatively related to systolic reactivity. However, these correlations suffered from the limited sample size and were not significant ( $p s \leq .10$, two-tailed). Therefore we will report below an analysis of the combined samples of both experiments.
Table 2 Zero-order correlations between the difficulty manipulation, subjective effort, SBP reactivity, and the assertiveness judgments in the assertive condition of Experiment 2

\begin{tabular}{llll}
\hline Variables & Subjective effort & SBP reactivity & Judgment \\
\hline Difficulty manipulation & $.74^{* * *}$ & $.52^{* *}$ & $-.41^{*}$ \\
Subjective effort & & $.49^{*}$ & $-.34^{+}$ \\
SBP reactivity & & & $-.35^{+}$ \\
\hline
\end{tabular}

$N=24 . \mathrm{SBP}=$ systolic blood pressure reactivity

${ }^{+} p \leq .10 ; * p \leq .05$ level; ** $p \leq .01 ; * * * p \leq .001$ (two-tailed)

Discussion

We found again that objective effort is mobilized in the ease-of-processing paradigm. When participants listed assertive behaviors, generating many, as opposed to few, examples elicited greater subjective and objective effort. Further, in the assertiveness condition, participants who listed many examples rated their own assertiveness as lower than participants who listed few examples. This pattern replicates the standard "ease" effect in the literature (Schwarz et al. 1991). We did not obtain the standard "ease" pattern in the unassertive situations. However, the results were still consistent with the theoretical assumptions because in this condition the task manipulation did influence neither subjective nor objective effort.

\section{Joint analysis}

The small sample sizes of Experiment 1 and the assertive condition of Experiment 2-where the manipulations had significant effects- did not yield sufficient statistical power to analyze the contributions of subjective and objective effort to the manipulation effect. Therefore we calculated $z$-scores of the measures of subjective effort, objective effort (SBP reactivity), and participants' judgments and merged the data sets of Experiment 1 and the assertive condition of Experiment 2 to obtain a sample size permitting a mediation analysis $(N=44)$. Note that the procedures, difficulty manipulations, and quantifications of the dependent variables were alike in these merged conditions.

We tested a full mediation model according to the principles of Baron and Kenny (1986). In a first step we tested if the difficulty manipulation had significant influences on the other three measures. This was the case for all measures, with $\beta=.74$ for subjective effort, $\beta=.52$ for SBP reactivity, and $\beta=-.43$ for the judgments, all $t \mathrm{~s}>3.09, p \mathrm{~s}<.01$. Next we tested if the two measures of effort were also significantly related to judgments. This was the case for subjective effort, $\beta=-.32, t(42)=$ $-2.17, p<.05$, but not for objective effort, $\beta=-.20$, $t(42)=-1.31, p>.20$, indicating that objective effort had 
no significant influence on the judgment effects. In summary this shows that the manipulation had significant effects on both objective and subjective effort, but that objective effort did not contribute to the judgment effects. We further explored the significant effect of subjective effort by analyzing how much of the manipulation effect on judgments can be explained by changes in subjective effort. To this end we conducted a regression analysis simultaneously entering the difficulty manipulation and subjective effort. This analysis revealed that the difficulty manipulation effect remained unchanged, $\beta=-.43, p<.05$, after including subjective effort into the regression and that subjective effort had no additional effect, $\beta=.01, p>.97$. We return to this finding in the discussion.

However, it is of note that our primary research question was if subjective effort or SBP reactivity contributed more to the judgment effects. Given the low statistical power for a full mediation model due to the limited sample size, we thus ran another analysis focusing on the relative contributions of subjective and objective effort, which were both significantly related to the difficulty manipulation. As presented in Fig. 3, subjective effort was positively related to SBP reactivity, $\beta=.40, t(42)=2.83, p<.01$. As already reported above, only the negative relationships between the judgments and subjective effort were significant $(p<.05)$, while the relationship between objective effort and judgments was not $(p>.20)$, already suggesting that objective effort played only a minor role in the ease effect on judgments. Most relevant, however, is that the negative path from subjective effort to the judgments remained intact when SBP reactivity was simultaneously entered into the regression, $\beta=-.28, t(41)=1.76, p<.05$ (one-tailed), while the relation between SBP reactivity and the judgments became even weaker, $\beta=-.09, t(41)=0.52, p>.50$. This indicates that subjective effort has a relatively greater effect on judgments in the ease-of-processing paradigm while objective effort has little or no effect on these judgments.

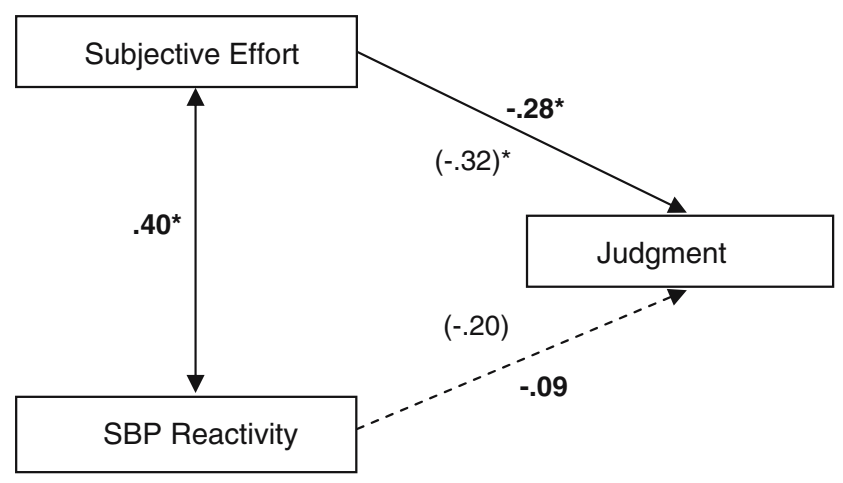

Fig. 3 Mediation analysis based on the merged samples of Experiment 1 and the assertive condition of Experiment $2(N=44)$. Pathcoefficients without parentheses give beta weights of a regression analysis including both subjective and objective effort as predictors

\section{General discussion}

The present experiments examined the role of objective effort in the "ease-of-retrieval" and "ease-of-argumentgeneration" paradigms (Schwarz 1998). In two experiments we found that subjective effort (measured via self-ratings) and objective effort (measured via cardiovascular reactivity) were higher when participants generated many (vs. few) arguments or instances of behavior. These findings suggest that the standard manipulations used in "ease paradigms" involve both subjective effort and objective effort. The fact that the ease paradigm does indeed seem to elicit genuine effort mobilization resonates with a large literature showing that effort in cognitive tasks can be tracked with psychophysiological measures (see Gendolla and Brinkmann 2005; Wright and Kirby 2001 for reviews).

As in previous research, participants' attitudes and judgments were influenced in a paradoxical way by the ease-of-processing manipulation (see Schwarz and Clore 2006, for a review). In Experiment 1, participants were more favorable towards private vehicles after generating many favorable arguments for public transport. In Experiment 2, participants evaluated themselves as less assertive after retrieving many assertive behaviors. This suggests that the implications of "what" (available content: how much information comes to mind) can be overridden by the experience of "how" (available experience: how that information comes to mind).

We also examined the respective contributions of subjective and objective effort to the judgment effects. A joint analysis of both experiments suggested that objective effort, even though it was elicited by the manipulation, had no influence on judgment. Moreover, controlling for objective effort did not change the impact of subjective effort on judgment, suggesting that in the ease-of-processing paradigm, if anything, subjective but not objective effort has an effect on judgment formation. This is an interesting result, given the findings of Stepper and Strack (1993) on the importance of bodily feedback or the results by Reber et al. (2004) showing that manipulations of objective difficulty can sometimes influence judgments without changing subjective effort.

Even though subjective effort had a significant impact on judgment, our analysis also showed that it could not explain variance in judgment over and above the manipulation in the full mediation model. This raises the question of how important the subjective perception of effort is for the judgmental "ease" effects. Several considerations bear on this issue. First, the link between subjective effort and the judgment effects in the literature is reasonably wellestablished. However, this conclusion is primarily based on the results of misattribution studies which eliminate the manipulation effect on judgment when subjective effort is 
undermined (for a review see Schwarz and Clore 2006). Interestingly, most ease-of-processing studies do not report mediation analyses and merely restrict themselves to reports of simple correlations (e.g., Aarts and Dijksterhuis 1999; Schwarz et al. 1991; Wänke et al. 1996; Norbert Schwarz, personal communication). Assuming this link, the nonsignificant mediation effect could be due to a lack of power because of the small sample size and to the additional noise caused by the somewhat more invasive measurement of physiological responses. Second, it is also possible that the difficulty manipulation may also have affected the judgments via other variables that we did not control. In fact, there is growing evidence that subjectively experienced effort is only one of many variables that can influence judgments in the "ease-of-retrieval paradigm". Thus, literature shows that judgment effects in this paradigm are influenced by variables such as imagined effort (Wänke et al. 1997), the difference between expected and experienced effort (Raghubir and Menon 2005; Hansen and Wänke in press), or confidence in the information conveyed by one's own thoughts (Tormala et al. 2002). Examining the role of these variables may help understand why the mediation from the manipulation to the judgment effects via subjective effort was not significant in the full mediation model.

Our studies also yielded some unexpected results. In the unassertiveness condition of Experiment 2, the "few-versus-many" manipulation did not influence subjective nor objective effort and, correspondingly, had no effect on judgments. One possible explanation for this finding is that effort will only be mobilized in proportion to task difficulty as long as success is possible and justifies the effort, and that disengagement occurs if a task appears to be too difficult or if success is not worth the necessary effort (Brehm and Self 1989; Wright 1996). In this condition of Experiment 2, the unpleasantness of listing many unassertive behaviors could have induced disengagement because of an additive effect on experienced demand due to negative affect (induced by the retrieval of unassertive behaviors) and high task difficulty (see Gendolla and Brinkmann 2005). If so, this would suggest an interesting boundary condition on the ease-ofretrieval effect. In fact, other studies also found effects of negative information to be weaker than those of positive information (e.g., Wänke et al. 1996).

Another point that deserves some discussion is that there were significant difficulty effects on both SBP and HR in Experiment 1, whereas Experiment 2 only found an effect on SBP. However, as mentioned in the introduction, it is a common finding that HR responds less reliably to task demand than SBP, most likely because HR is both sympathetically and parasympathetically mediated, while SBP is sympathetically mediated and systematically related to myocardial constriction (Brownley et al. 2000; Obrist 1981;
Wright 1996). Thus, SBP is the more sensitive measure of task engagement (see also Gendolla and Richter 2005, 2006).

Conclusion and outlook

The present studies showed for the first time that the classic "ease-of-processing" paradigm involves not only changes in subjective effort, but also objective effort, as assessed by psychophysiological measures. Our analyses suggested that subjective effort is significantly related to judgments, although its role in mediating the impact of the few/many manipulation is less clear. More importantly, our analyses showed that objective effort had a negligible effect on judgments. However, our first attempt to measure objective effort with cardiovascular measures may be complemented with investigations of other physiological contributors to effort experience such as feedback from the muscular, hormonal, and somatosensory systems (e.g., Craig 2002).

Acknowledgments This research was supported by a research grant (Ge 987/7-1) from the Deutsche Forschungsgemeinschaft awarded to the second author, and from the National Science Foundation (BCS0217294) to the third author. We would like to thank Norbert Schwarz for helpful discussions, Alexandra Russell and Annick Tinembart for their help in the data collection as hired experimenters, and Troy Chenier for helpful comments.

Open Access This article is distributed under the terms of the Creative Commons Attribution Noncommercial License which permits any noncommercial use, distribution, and reproduction in any medium, provided the original author(s) and source are credited.

\section{References}

Aarts, H., \& Dijksterhuis, A. (1999). How often did I do it? Experienced ease of retrieval and frequency estimates of past behavior. Acta Psychologica, 103, 77-89.

Baron, R. M., \& Kenny, D. A. (1986). The moderator-mediator variable distinction in social psychological research: Conceptual, strategic, and statistical considerations. Journal of Personality and Social Psychology, 51, 1173-1182.

Berntson, G. G., Cacioppo, J. T., \& Quigley, K. S. (1993). Cardiac psychophysiology and autonomic space in humans: Empirical perspectives and conceptual implications. Psychological Bulletin, 114, 296-322.

Brehm, J. W., \& Self, E. A. (1989). The intensity of motivation. Annual Review of Psychology, 40, 109-131.

Brehm, J. W., Wright, R. A., Solomon, S., Silka, L., \& Greenberg, J. (1983). Perceived difficulty, energization, and the magnitude of goal valence. Journal of Experimental Social Psychology, 19, 21-48.

Brownley, K. A., Hurwitz, B. E., \& Schneiderman, N. (2000). Cardiovascular psychophysiology. In J. T. Cacioppo, L. G. Tassinary, \& G. G. Berntson (Eds.), Handbook of psychophysiology (pp. 224-264). New York: Cambridge University Press.

Craig, A. D. (2002) How do you feel? Interoception: The sense of the physiological condition of the body. Nature Reviews Neuroscience, 3, 655-666. 
Csikszentmihalyi, M. (1975). Beyond boredom and anxiety. San Francisco: Jossey-Bass.

Fazendeiro, T., Winkielman, P., Luo, C., \& Lorah, C. (2005). False recognition across meaning, language, and stimulus format: Conceptual relatedness and the feeling of familiarity. Memory and Cognition, 33, 249-260.

Gendolla, G. H. E., \& Brinkmann, K. (2005). The role of mood states in self-regulation: Effects on action preferences and resource mobilization. European Psychologist, 10, 187-198.

Gendolla, G. H. E., \& Koller, M. (2001). Surprise and motivation of causal search: How are they affected by outcome valence and importance? Motivation and Emotion, 25, 327-349.

Gendolla, G. H. E., \& Krüsken, J. (2002). The joint effect of informational mood impact and performance-contingent incentive on effort-related cardiovascular response. Journal of Personality and Social Psychology, 83, 271-283.

Gendolla, G. H. E., \& Richter, M. (2005). Ego-involvement and effort: Cardiovascular, electrodermal, and performance effects. Psychophysiology, 42, 595-603.

Gendolla, G. H. E., \& Richter, M. (2006). Ego-involvement and the difficulty law of motivation: Effects on effort-related cardiovascular response. Personality and Social Psychology Bulletin, 32, 1188-1203.

Gerin, W., Litt, M. D., Deich, J., \& Pickering, T. G. (1995). Selfefficacy as a moderator of perceived control effects on cardiovascular reactivity: Is enhanced control always beneficial? Psychosomatic Medicine, 57, 390-397.

Hansen, J., \& Wänke, M. (in press). It's the difference that counts: Expectancy/experience discrepancy moderates the use of ease of retrieval in attitude judgments. Social Cognition.

Jacoby, L. L., Kelley, C. M., Brown, J., \& Jaeschko, J. (1989). Becoming famous overnight: Limits of the ability to avoid unconscious influences of the past. Journal of Personality and Social Psychology, 56, 326-338.

Light, K. C. (1981). Cardiovascular responses to effortful active coping: Implications for the role of stress in hypertension development. Psychophysiology, 18, 216-225.

Llabre, M. M., Spitzer, S. B., Saab, P. G., Ironson, G. H., \& Schneiderman, N. (1991). The reliability and specificity of delta versus residualized change as measure of cardiovascular reactivity to behavioral challenges. Psychophysiology, 28, 701-711.

Morsella, E. (2005). The function of phenomenal states: Supramodular interaction theory. Psychological Review, 112, 1000-1021.

Nisbett, R. E., \& Wilson, T. D. (1977). Telling more than we can know: Verbal reports on mental processes. Psychological Review, 84, 231-259.

Obrist, P. A. (1981). Cardiovascular psychophysiology. New York: Plenum.

Obrist, P. A., Howard, J. L., Lawler, J. E., Galosy, R. A., Meyers, K. A., \& Gaebelein, C. J. (1974). The cardiac-somatic interaction. In P. A. Obrist, et al. (Eds.), Cardiovascular psychophysiology: Current issues in response mechanisms, biofeedback and methodology (pp. 137-162). Chicago, IL: Aldine.

Pyszczynski, T., \& Greenberg, J. (1987). Toward an integration of cognitive and motivational perspectives on social inference: A biased hypothesis-testing model. In L. Berkowitz (Ed.), Advances in experimental social psychology (Vol. 20, pp. 297340). New York: Academic Press.

Raghubir, P., \& Menon, G. (2005). When and why is ease of retrieval informative? Memory and Cognition, 33, 821-832.

Reber, R., Wurtz, P., \& Zimmermann, T. D. (2004). Exploring "fringe"' consciousness: The subjective experience of perceptual fluency and its objective bases. Consciousness and Cognition, $13,47-60$.
Rothman, A. J., \& Schwarz, N. (1998). Constructing perceptions of vulnerability: Personal relevance and the use of experiential information in health judgments. Personality and Social Psychology Bulletin, 24, 1053-1064.

Schwarz, N. (1998). Accessible content and accessibility experiences: The interplay of declarative and experiential information in judgment. Personality and Social Psychology Review, 2, 87-99.

Schwarz, N. (1999). Self-reports: How the questions shape the answers. American Psychologist, 54, 93-105.

Schwarz, N., Bless, H., Strack, F., Klumpp, G., Rittenauer-Schatka, H., \& Simons, A. (1991). Ease of retrieval as information: Another look at the availability heuristic. Journal of Personality and Social Psychology, 61, 195-202.

Schwarz, N., \& Clore, G. L. (2006). Feelings and phenomenal experiences. In E. T. Higgins \& A. Kruglanski (Eds.), Social psychology. A handbook of basic principles (2nd ed.). New York: Guilford Press.

Shapiro, D., Jamner, L. D., Lane, J. D., Light, K. C., Myrtek, M., Sawada, Y., \& Steptoe, A. (1996). Blood pressure publication guidelines. Psychophysiology, 33, 1-12.

Sherwood, A., Dolan, C. A., \& Light, K. C. (1990). Hemodynamics of blood pressure responses during active and passive coping. Psychophysiology, 27, 656-668.

Silvia, P. J., \& Gendolla, G. H. E. (2001). On introspection and selfperception: Does self-focused attention enable accurate selfknowledge? Review of General Psychology, 5, 241-269.

Smith, T. W., Ruiz, J. M., \& Uchino, B. N. (2000). Vigilance, active coping, and cardiovascular reactivity during social interaction in young men. Health Psychology, 19, 382-392.

Stepper, S., \& Strack, F. (1993). Proprioceptive determinants of emotional and nonemotional feelings. Journal of Personality and Social Psychology, 64, 11-220.

Tormala, Z. L., Petty, R. E., \& Briñol, P. (2002). Ease of retrieval effects in persuasion: A self-validation analysis. Personality and Social Psychology Bulletin, 28, 1700-1712.

Tversky, A., \& Kahneman, D. (1973). Availability: A heuristic for judging frequency and probability. Cognitive Psychology, 5, 207-232.

Wänke, M., Bless, H., \& Biller, B. (1996). Subjective experience versus content of information in the construction of attitude judgments. Personality and Social Psychology Bulletin, 22, 1105-1113.

Wänke, M., Bohner, G., \& Jurkowitsch, A. (1997). There are many reasons to drive a BMW: Does imagined ease of argument generation influence attitude? Journal of Consumer Research, 24, 170-177.

Winkielman, P., \& Schwarz, N. (2001). How pleasant was your childhood? Beliefs about memory shape inferences from experienced difficulty of recall. Psychological Science, 12, 176-179.

Winkielman, P., Schwarz, N., \& Belli, R. F. (1998). The role of ease of retrieval and attribution in memory judgments: Judging your memory as worse despite recalling more events. Psychological Science, 9, 124-126.

Wright, R. A. (1996). Brehm's theory of motivation as a model of effort and cardiovascular response. In P. M. Gollwitzer \& J. A. Bargh (Eds.), The psychology of action: Linking cognition and motivation to behavior (pp. 424-453). New York: Guilford.

Wright, R. A., \& Kirby, L. D. (2001). Effort determination of cardiovascular response: An integrative analysis with applications in social psychology. In M. P. Zanna (Ed.), Advances in experimental social psychology (Vol. 33, pp. 255-307). New York: Academic Press.

Wright, R. A., Martin, R. E., \& Bland, J. L. (2003). Energy resource depletion, task difficulty, and cardiovascular response to a mental arithmetic challenge. Psychophysiology, 40, 98-105. 